\title{
THE
}

\section{Cyclodextrin-Enhanced Extraction and Energy Transfer of Carcinogens in Complex Oil Environments}

\author{
Nicole Serio \\ University of Rhode Island \\ Chitapom Chanthalyma \\ University of Rhode Island \\ Lindsey Prignano \\ University of Rhode Island \\ Mindy Levine \\ University of Rhode Island, m_levine@uri.edu
}

Follow this and additional works at: https://digitalcommons.uri.edu/chm_facpubs

The University of Rhode Island Faculty have made this article openly available.

Please let us know how Open Access to this research benefits you.

This is a pre-publication author manuscript of the final, published article.

Terms of Use

This article is made available under the terms and conditions applicable towards Open Access

Policy Articles, as set forth in our Terms of Use.

\section{Citation/Publisher Attribution}

Serio, N., Chanthalyma, C., Prignano, L., \& Levine, M. (2013). Cyclodextrin-Enhanced Extraction and Energy Transfer of Carcinogens in Complex Oil Environments. ACS Applied Materials \& Interfaces, 5(22), 11951-11957. doi: 10.1021/am403702n Available at: http://dx.doi.org/10.1021/am403702n 


\section{Cyclodextrin-Enhanced Extraction and Energy}

\section{Transfer of Carcinogens in Complex Oil}

\section{Environments}

Nicole Serio, Chitapom Chanthalyma, Lindsey Prignano, and Mindy Levine*

Department of Chemistry, University of Rhode Island, 51 Lower College Road, Kingston, RI 02881; mlevine@chm.uri.edu; 401-874-4243

KEYWORDS Oil, polycyclic aromatic hydrocarbons, cyclodextrin, energy transfer, fluorescence spectroscopy

ABSTRACT Reported herein is the use of $\gamma$-cyclodextrin for two tandem functions: (a) the extraction of carcinogenic polycyclic aromatic hydrocarbons (PAHs) from oil samples into aqueous solution, and (b) the promotion of highly efficient energy transfer from the newly extracted PAHs to a high-quantum yield fluorophore. The extraction proceeded in moderate to good efficiencies, and the resulting cyclodextrin-promoted energy transfer lead to a new, brightly fluorescent signal in the aqueous solution. The resulting dual-function system (extraction followed by energy transfer) has significant relevance in the environmental detection and cleanup of oil spill-related carcinogens. 


\section{Introduction:}

Significant oil spills in recent years ${ }^{1}$ have highlighted a number of pressing medical ${ }^{2,3}$ and environmental ${ }^{4,5}$ problems associated with oil spill cleanup, ${ }^{6}$ post-incident monitoring of toxins, ${ }^{7}$ and the prevention of future oil spills. Such problems include the long-term environmental persistence of highly toxic polycyclic aromatic hydrocarbons (PAHs) (including the known carcinogen benzo[a]pyrene), ${ }^{8,9}$ and the accumulation of PAHs at various points in the food chain. ${ }^{10-13}$

Methods for removing PAHs from the environment include (a) the biodegradation of PAHs into less toxic products; ${ }^{14}$ (b) the sequestration of PAHs by applying chemical reagents such as surfactants ${ }^{15}$ or cyclodextrins; ${ }^{16-18}$ (c) the segregation of PAHs from contaminated air using aerosol filters; and (d) the removal of PAHs from contaminated solutions using molecularly imprinted polymers ${ }^{19}$ or covalently-immobilized anthracene sensors. ${ }^{20}$

Once the PAHs have been separated from the environment, accurately identifying them usually requires multiple steps, including (a) isolating a mixture of toxins from a crude environmental sample; (b) separating the small-molecule toxins by chromatography; and (c) identifying the PAHs based on their molecular weights, fluorescence spectra, or chromatographic retention times. ${ }^{21}$ An efficient system that can both isolate PAHs from complex environments and accurately identify the PAHs has not yet been reported.

$\gamma$-cyclodextrin is a potential candidate for the tandem isolation and identification of PAHs. In addition to its well-established ability to bind PAHs, ${ }^{22,23}$ we recently reported that $\gamma$-cyclodextrin promotes highly efficient energy transfer from PAHs to a series of small-molecule fluorophores. ${ }^{24-26}$ This energy transfer occurs as a result of the enforced proximity of the donor and acceptor when bound simultaneously in the $\gamma$-cyclodextrin cavity, ${ }^{27,28}$ and is efficient for a 
broad range of substrates in complex biological media. Thus, a scheme involving $\gamma$-cyclodextrin can simultaneously sequester PAHs from complex media and facilitate energy transfer to a fluorophore within the sample, thus providing key information: that the sample of interest contains potentially toxic PAHs and will require further analysis and decontamination.

Reported herein is the successful implementation of a $\gamma$-cyclodextrin-based system to accomplish these two key functions: (a) extracting PAHs from complex oils and binding them with moderate to good efficiencies; and (b) promoting non-covalent, proximity-induced energy transfer from the isolated PAHs to a high quantum yield BODIPY fluorophore. The oils used in these investigations (vacuum pump oil, motor oil, vegetable oil, and cod liver oil) contain varying levels of PAH contaminants: from no known PAHs in cod liver oil, ${ }^{29,30}$ to small amounts of PAHs in several types of vegetable oil, ${ }^{31,32}$ and large quantities of PAHs in used motor oil. ${ }^{33}$ These 'innate' PAH amounts were detected by measuring the energy transfer efficiencies from 'undoped' oil samples to the fluorophore. Samples were separately 'doped' with small amounts of concentrated PAH solutions, which adds to the innate PAHs found in the oils and allows for a robust PAH-to-fluorophore energy transfer signal. In addition to investigating the ability of a buffered solution of $\gamma$-cyclodextrin to extract and bind toxic PAHs, we also investigated an "oilspill-like scenario": cyclodextrin was dissolved in Narragansett Bay seawater where it was still able to extract PAHs with moderate efficiencies from motor oil samples.

This system of extraction followed by energy transfer has a number of advantages compared to previously-reported methods for the detection of PAHs, including the ability to easily modulate the fluorescence signal generated from the energy transfer via judicious choice of fluorophore. Results reported herein used BODIPY-based fluorophore 6; however, a simple replacement of this fluorophore with other known structures will lead to a fluorescence emission signal at a 
different wavelength. The ability to use a variety of fluorophores with different emission maxima

will allow for the facile development of an array-based detection system. ${ }^{34}$ In such a system, each analyte will interact differently with a set of fluorophores bound in cyclodextrin. Statistical analysis of the resulting response patterns will enable the selective detection of highly toxic PAHs, which is an exciting application of the results reported herein. ${ }^{35}$ Overall, this dualfunction system has significant potential applications for the isolation and detection of carcinogenic PAHs in complex, real-world environments.

\section{Experimental Procedures}

Materials and methods: Four oils were analyzed: Crisco soybean oil, Fisherbrand 19 mechanical pump fluid oil, Pennzoil SAE-5W30 motor oil, and CVS Brand Cod Liver Oil. Compounds 1-5 were obtained from Sigma-Aldrich chemical company (Chart 1) and used as received, and compound 6 was synthesized following literature-reported procedures (Chart 1). ${ }^{36,37}$

Fluorescence measurements were recorded on a Shimadzu RF 5301 spectrophotometer (1.5 nm excitation slit width and $1.5 \mathrm{~nm}$ emission slit width). All spectra were integrated vs. wavenumber on the $\mathrm{X}$-axis using OriginPro software.

PAH extraction experiments were conducted as follows: For vegetable oil, cod liver oil, and pump oil: $2.5 \mathrm{~mL}$ of the oil sample was mixed with $20 \mu \mathrm{L}$ of a $1 \mathrm{mg} / \mathrm{mL}$ solution of each analyte (1-5) in tetrahydrofuran (THF). This oil mixture was then added to $2.5 \mathrm{~mL}$ of an aqueous solution: either $10 \mathrm{mM}$ of $\gamma$-cyclodextrin in phosphate buffered saline (PBS) or $0 \mathrm{mM}$ solution of $\gamma$-cyclodextrin in PBS (control). The oil and water mixture was vigorously shaken by hand (for approximately 1 minute) to allow thorough mixing, and the layers were separated by allowing the vial to sit undisturbed for 16-24 hours. The analyte in each layer was detected by fluorescence spectroscopy: excitation of the analyte near its absorption maximum (compounds 1- 
3; $360 \mathrm{~nm}$ excitation; compound 4: $270 \mathrm{~nm}$ excitation; compound 5: $290 \mathrm{~nm}$ excitation), followed by integration of the fluorescence emission spectrum of the analyte vs. wavenumber on the $\mathrm{X}$-axis (using OriginPro software).
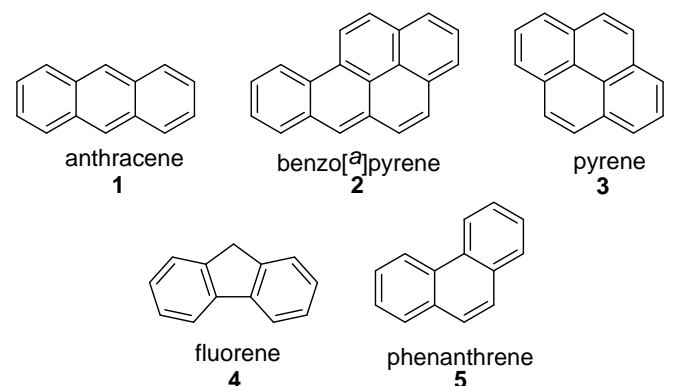

torene

5

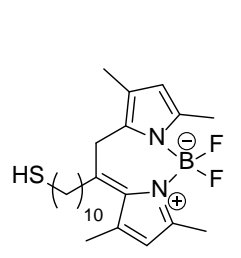

BODIPY fluorophore
6

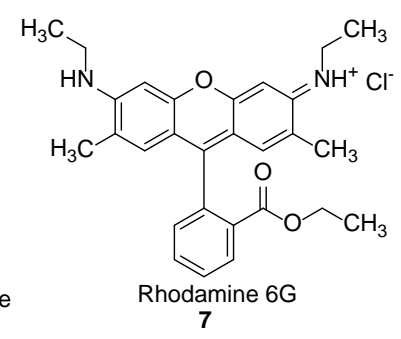

Chart 1: Polycyclic aromatic hydrocarbons (1-5) and fluorophores (6-7) investigated

The comparison of the analyte in each layer was quantified according to Equation 1:

Analyte comparison $=I_{\text {aqueous }} / I_{\text {oil }}($ Eq. 1$)$

where $I_{\text {aqueous }}=$ the integrated emission of the analyte in the aqueous layer, and $I_{\text {oil }}=$ the integrated emission of the analyte in the oil layer.

Modification for motor oil experiments: Due to difficulties in achieving a full separation of the motor oil from the aqueous layer, the motor oil was first diluted with an equal amount of $n$ hexanes (1.25 mL of motor oil and $1.25 \mathrm{~mL}$ of $n$-hexanes). This diluted mixture was further mixed with $20 \mu \mathrm{L}$ of the analyte solution in THF, followed by addition to $2.5 \mathrm{~mL}$ of the aqueous layer (either $10 \mathrm{mM}$ or $0 \mathrm{mM}$ of $\gamma$-cyclodextrin in PBS). Seawater-based experiments were 
conducted by mixing the motor oil/hexane mixture with cyclodextrin dissolved in Narrangasett Bay seawater, followed by separation of the layers and analysis via fluorescence spectroscopy.

Energy transfer experiments were conducted as follows: $100 \mu \mathrm{L}$ of compound $6(0.1 \mathrm{mg} / \mathrm{mL}$ in THF), $20 \mu \mathrm{L}$ of the analyte of interest (1.0 mg/mL in THF), $2.5 \mathrm{~mL}$ of the oil of interest (cod liver oil, pump oil, or vegetable oil), and $2.5 \mathrm{~mL}$ of the aqueous solution (either $0 \mathrm{mM} \gamma$ cyclodextrin or $10 \mathrm{mM} \gamma$-cyclodextrin in PBS) were combined in a vial. The layers were shaken to allow thorough mixing, left undisturbed for 16-24 hours, and the aqueous and oil layers were then separated. Each layer was excited at both the excitation wavelength of the PAH (270 nm, $290 \mathrm{~nm}$ or $360 \mathrm{~nm})$ and at the excitation wavelength of compound $6(460 \mathrm{~nm})$. The energy transfer efficiency is defined according to Equation 2:

Energy transfer efficiency $=I_{\mathrm{DA}} / I_{\mathrm{A}} \times 100 \%(\mathrm{Eq} 2)$

Where $I_{\mathrm{DA}}$ is the integration of the fluorophore emission from analyte excitation and $I_{\mathrm{A}}$ is the integrated fluorophore emission from direct excitation. An illustration of such energy transfer for a generic donor-acceptor pair is shown in Figure 1.

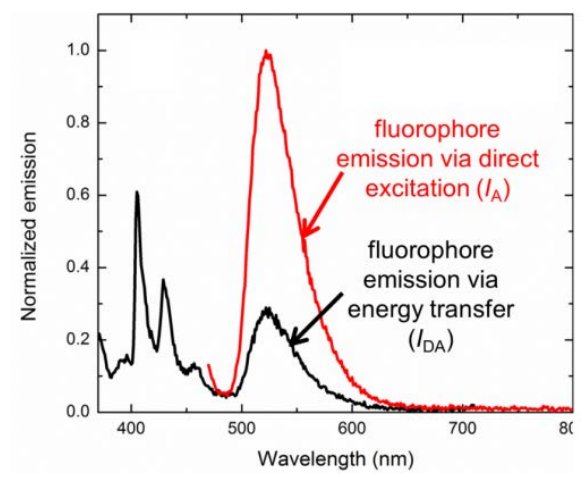

Figure 1. Illustration of energy transfer efficiency for a generic donor-acceptor pair.

Energy transfer from the oil directly was also measured by omitting the analyte from the 
procedure detailed above. After the aqueous and oil layers were separated, the energy transfer in the oil layer was quantified by exciting the oil at the analyte excitation wavelengths ( $270 \mathrm{~nm}$, $290 \mathrm{~nm}$, and $360 \mathrm{~nm}$ ) but in the absence of any analyte, and by exciting the mixture at the fluorophore’s excitation wavelength. The fluorophore emission via indirect excitation was compared to the fluorophore emission via direct excitation to determine the energy transfer efficiencies.

Modification for motor oil experiments: The motor oil was diluted with an equal volume of $n$ hexanes (1.25 $\mathrm{mL}$ of each), followed by addition of the fluorophore, analyte, and aqueous solution (either PBS or seawater with $10 \mathrm{mM} \gamma$-cyclodextrin (or controls without $\gamma$ cyclodextrin)). All subsequent steps were conducted according to the procedure detailed above.

Control experiments were conducted as follows: Compound $\mathbf{6}$ was excited at the excitation wavelength of the analyte $(270 \mathrm{~nm}, 290 \mathrm{~nm}$, and $360 \mathrm{~nm}$ ) in the absence of the analyte and in the presence of the analyte. A “control ratio" was defined according to Equation 3:

Control ratio $=I_{\text {fluorophore-analyte }} / I_{\text {fluorophore-control }}(\mathrm{Eq} 3)$,

Where $I_{\text {fluorophore-analyte }}$ is the integration of the fluorophore emission in the presence of the analyte; and $I_{\text {fluorophore-control }}$ is the ratio of the fluorophore emission in the absence of the analyte. Ratios greater than 1.05 were taken to represent cases of legitimate energy transfer. Ratios close to 1 indicated that no significant energy transfer was occurring, and that the existence of a fluorophore peak via analyte excitation was merely a result of the fluorophore having a non-zero absorbance at that particular wavelength. These control ratios were measured in both the oil layer and aqueous layer (full results are reported in the ESI). 


\section{Results and Discussion}

The two functions of this cyclodextrin-based system (extraction and energy transfer) will be discussed individually:

1. Extraction of PAHs using $\gamma$-cyclodextrin. To measure the ability of $\gamma$-cyclodextrin to extract PAHs from complex oils into an aqueous environment, oil samples were doped with small amounts of PAH analytes (compounds 1-5). The PAH-doped samples were then mixed with an equal volume of an aqueous solution (either $10 \mathrm{mM}$ or $0 \mathrm{mM}$ of $\gamma$-cyclodextrin), and the amount of analyte in the aqueous layer was quantified. The amount of analyte extracted with a $10 \mathrm{mM} \gamma$ cyclodextrin solution was compared to the amount extracted with a $0 \mathrm{mM} \gamma$-cyclodextrin control solution, and the result defined as an "Enhancement factor" according to Equation 4:

Enhancement factor $=$ Analyte comparison with $10 \mathrm{mM} \gamma$-cyclodextrin $/$ analyte comparison with $0 \mathrm{mM} \gamma$-cyclodextrin (Eq. 4)

Table 1. Enhancement factors (E. F.) of analytes 1-5 in all oil sources ${ }^{a}$

\begin{tabular}{|c|c|c|c|c|c|}
\hline $\begin{array}{c}\text { Compound } \\
\#\end{array}$ & $\begin{array}{c}\text { E. F. in } \\
\text { motor oil }\end{array}$ & $\begin{array}{c}\text { E. F. in } \\
\text { vegetable oil }\end{array}$ & $\begin{array}{c}\text { E. F. in pump } \\
\text { oil }\end{array}$ & $\begin{array}{c}\text { E. F. in cod } \\
\text { liver oil }\end{array}$ & $\begin{array}{c}\text { E. F. in motor } \\
\text { oil-seawater }\end{array}$ \\
\hline $\mathbf{1}$ & $1.86 \pm 0.46$ & $0.80 \pm 0.13$ & $0.99 \pm 0.53$ & $1.06 \pm 0.10$ & $0.97 \pm 0.03$ \\
\hline $\mathbf{2}$ & $2.11 \pm 0.36$ & $0.89 \pm 0.39$ & $1.03 \pm 0.59$ & $1.11 \pm 0.05$ & $0.92 \pm 0.07$ \\
\hline $\mathbf{3}$ & $1.56 \pm 0.36$ & $0.87 \pm 0.08$ & $1.07 \pm 0.53$ & $1.14 \pm 0.05$ & $0.84 \pm 0.06$ \\
\hline $\mathbf{4}$ & $b$ & $b$ & $0.99 \pm 0.17$ & $1.13 \pm 0.04$ & $1.11 \pm 0.07$ \\
\hline $\mathbf{5}$ & $1.79 \pm 0.69$ & $b$ & $1.02 \pm 0.34$ & $1.15 \pm 0.06$ & $1.01 \pm 0.06$ \\
\hline
\end{tabular}

$a$ All data represents an average of at least five trials

$b$ No analyte was found in the oil layer

Table 1 highlights some significant differences in the ability of the $10 \mathrm{mM} \gamma$-cyclodextrin solutions to extract analytes from complex oils. These enhancement factors are based on a 
complicated interplay of factors, including: (a) the binding constant of the analytes in $\gamma$ cyclodextrin; (b) the physicochemical properties of the complex oils; and (c) the solubilities of the analytes in oil compared to water. The potential contributions of each of these factors are discussed in turn:

1a. $\gamma$-Cyclodextrin binding constants. Binding affinities of analytes 1-5 are shown in Table 2. The fact that all binding constants are similar (the largest value is only 1.3 times the smallest value) indicates that the differences in binding are unlikely to be responsible for the differential behavior of the analytes in the oil extraction experiments.

Table 2. Analyte binding constants

\begin{tabular}{|c|c|}
\hline Compound \# & $\begin{array}{c}\text { Literature-reported binding } \\
\text { constants in } \gamma \text {-cyclodextrin }\end{array}$ \\
\hline $\mathbf{1}$ & $335 \mathrm{M}^{-1}$ \\
\hline $\mathbf{2}$ & $a$ \\
\hline $\mathbf{3}$ & $294 \mathrm{M}^{-1}$ \\
\hline $\mathbf{4}$ & $258 \mathrm{M}^{-1}$ \\
\hline $\mathbf{5}$ & $332 \mathrm{M}^{-1}$ \\
\hline
\end{tabular}

$a$ The binding constant of benzo[a]pyrene in $\gamma$-cyclodextrin was not reported in the literature; attempts to calculate the binding constant directly were unsuccessful, likely due to a complex equilibrium between binary and ternary complexes.

$1 b$. The identity of the oil. The extraction efficiencies varied greatly depending on the particular oil. For motor oil extractions with cyclodextrin-doped PBS, the $10 \mathrm{mM} \gamma$-cyclodextrin layer contained substantially more PAH analyte compared to the $0 \mathrm{mM} \gamma$-cyclodextrin control for all analytes. Two examples of the high enhancement factors in motor oil extraction experiments are shown in Figure 2, for analytes $\mathbf{1}$ (Figure 2A) and $\mathbf{5}$ (Figure 2B). 


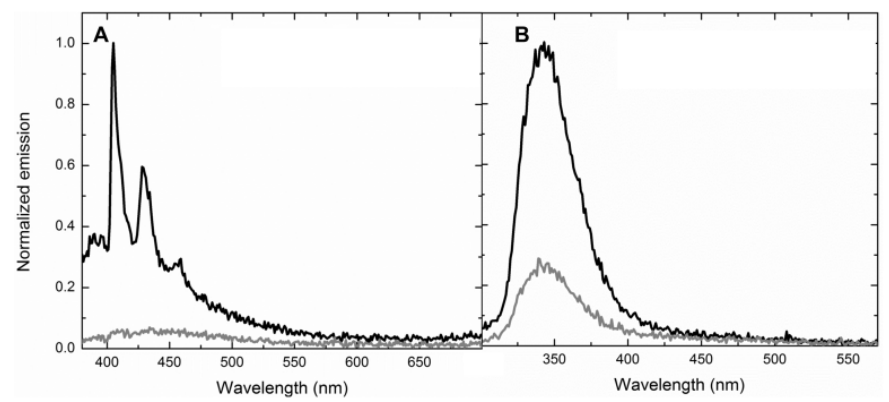

Figure 2. A comparison of the amount of analyte extracted from motor oil with $10 \mathrm{mM} \gamma$ cyclodextrin in PBS and 0 mM $\gamma$-cyclodextrin in PBS for (A) compound 2; and (B) compound 5. The black line represents the analyte extracted with $10 \mathrm{mM} \gamma$-cyclodextrin and the grey line represents the analyte extracted with $0 \mathrm{mM} \gamma$-cyclodextrin.

For vacuum pump oil, vegetable oil, and cod liver oil, the enhancement factors for all analyte-oil combinations were much closer to 1 , indicating limited contributions by $\gamma$-cyclodextrin to PAH extractions. These results contrast with a recent report that showed enhanced extraction efficiencies using hydroxypropyl- $\beta$-cyclodextrin to remove PAHs from contaminated soil. ${ }^{38}$ The difference between these reported results and the relatively modest efficiencies reported herein is likely a result of the increased binding affinities of the PAHs in hydroxypropyl- $\beta$-cyclodextrin compared to their more modest affinities in $\gamma$-cyclodextrin (Table 2).

Interestingly, the motor oil-seawater series demonstrated different behavior than the motor oilPBS series, with lower enhancement factors for all seawater cases (and enhancement factors less than 1 for analytes 1-3). The fact that the enhancement factors for analytes $\mathbf{4}$ and $\mathbf{5}$ are greater than 1 is likely a result of their increased solubility in water compared to compounds 1-3. Reasons for this atypical behavior in motor oil-seawater extractions may be related to the particular properties of the seawater, including the presence of surfactants and the high salt content. 
(a) Surfactants: Sea water is known to contain high concentrations of surfactants. ${ }^{39}$ These surfactants can form micelles that bind the PAH donor and the BODIPY acceptor in the hydrophobic interior, ${ }^{40}$ thereby interfering with the ability of the cyclodextrin to form the necessary ternary complexes.

(b) High salt concentration: The high salinity of sea water can also affect the ability of the cyclodextrin to form ternary complexes and promote energy transfer. ${ }^{41}$ This complex formation is largely driven by hydrophobic binding, which is known to depend heavily on salt concentration. ${ }^{42,43}$ Preliminary experiments using a phosphate buffer without saline (but under otherwise identical conditions) indicated that substantially more analyte was extracted into $\gamma$ cyclodextrin dissolved in phosphate buffer (saline-free) compared to $\gamma$-cyclodextrin dissolved in sea water (for example, the analyte comparison for pyrene is 0.34 in seawater compared to 0.75 in phosphate buffer). The high salinity of sea water is thus expected to lead to a further decrease in the hydrophobic binding necessary for cyclodextrin-promoted energy transfer.

1c. Solubility of analytes in oil and aqueous layers. The solubilities of PAHs 1-5 vary widely, with compounds $\mathbf{4}$ and $\mathbf{5}$ having markedly higher aqueous solubilities compared to compounds $\mathbf{1}$ $3{ }^{44}$ This increased solubility had no measurable effect on the observed enhancement factors for most extraction series (motor oil, vegetable oil, pump oil, and cod liver oil). However, the seawater-motor oil extractions demonstrated greater enhancement factors for analytes $\mathbf{4}$ and $\mathbf{5}$ compared to analytes 1-3. These results demonstrate that the solubility of the analytes can facilitate the cyclodextrin-promoted extraction and binding.

2. Energy transfer from PAHs to fluorophore 6. The extraction of PAHs into the aqueous layer proceeded with moderate efficiencies in most cases. Even in cases of low extraction efficiencies, 
many of the analytes underwent efficient energy transfer to the highly fluorescent energy acceptor 6. The results are summarized in Table 3, and the results of energy transfer from a sample analyte (compound 2) to fluorophore 6 are shown in Figure 3.

Table 3. Energy transfer efficiencies from PAHs (1-5) to compound 6 in the $10 \mathrm{mM} \gamma$ cyclodextrin extracts $^{\mathrm{a}}$

\begin{tabular}{|c|c|c|c|c|c|}
\hline Compound \# & Motor oil & Vegetable oil & Pump oil & Cod liver oil & $\begin{array}{c}\text { Motor oil- } \\
\text { seawater }\end{array}$ \\
\hline $\mathbf{1}$ & $71 \pm 1 \%$ & $32 \pm 6 \%$ & $35 \pm 0.1 \%$ & $31 \pm 2 \%$ & $72 \pm 4 \%$ \\
\hline $\mathbf{2}$ & $72 \pm 2 \%$ & $29 \pm 0.1 \%$ & $34 \pm 2 \%$ & $32 \pm 2 \%$ & $72 \pm 2 \%$ \\
\hline $\mathbf{3}$ & $71 \pm 1 \%$ & $33 \pm 5 \%$ & $35 \pm 3 \%$ & $33 \pm 2 \%$ & $69 \pm 4 \%$ \\
\hline $\mathbf{4}$ & $45 \pm 8 \%$ & $b$ & $b$ & $b$ & $b$ \\
\hline $\mathbf{5}$ & $18 \pm 5 \%$ & $b$ & $31 \pm 4 \%$ & $b$ & $b$ \\
\hline
\end{tabular}

$a$ All data represents an average of at least five trials

$b$ No energy transfer was observed

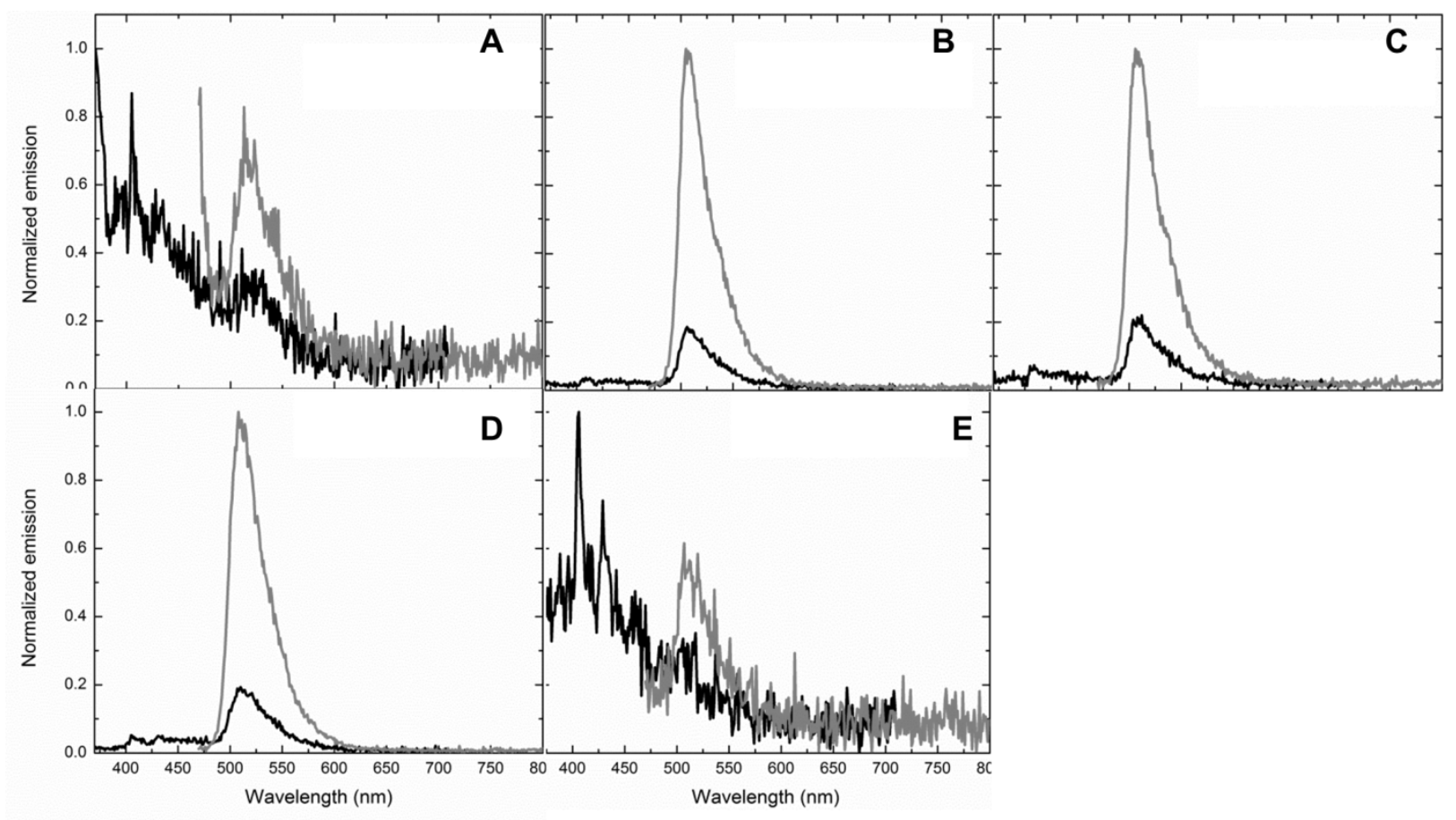


Figure 3. Examples of energy transfer from analyte 2 to fluorophore 6 in $10 \mathrm{mM} \gamma$-cyclodextrin in PBS extracted from: (A) motor oil, (B) vegetable oil; (C) pump oil; (D) cod liver oil; and (E) in $10 \mathrm{mM} \gamma$-cyclodextrin in seawater extracted from motor oil. The black line represents analyte excitation and the grey line represents direct fluorophore excitation.

The efficient detection of benzo[a]pyrene $\mathbf{2}$ is particularly important due to its high toxicity and known carcinogenicity. ${ }^{45,46}$ The results summarized in Figure 3 demonstrate that benzo[a]pyrene can participate efficiently in extraction and energy transfer across a broad range of complex oils.

There are a number of other aspects of this energy transfer that merit discussion.

2a. Quantifying fluorophore partitioning. Energy transfer occurred in the aqueous layer despite the fact that the majority of compound 6 remained in the oil layer (motor oil: $87 \pm 3 \%$; vegetable oil: $94 \pm 3 \%$; pump oil: $93 \pm 6 \%$; cod liver oil: $86 \pm 12 \%$; motor oil-seawater: $87 \pm 3 \%$ ). In all cases, the energy transfer in $10 \mathrm{mM} \gamma$-cyclodextrin was substantially more efficient compared to the energy transfer in the oil layer (see ESI for details), despite the limited amount of fluorophore in the aqueous environment.

2b. Energy transfer comparisons. Figure 4 shows comparisons of the emission spectra for analytes 1-5 that were extracted from motor oil, in the absence and presence of fluorophore $\mathbf{6}$. This figure highlights a key advantage of non-covalent energy transfer, which is the ability to achieve a bright fluorescent signal at a targeted wavelength. The direct fluorescence emission of analytes 1-5 in the extracted aqueous layer is relatively weak, because the majority of the analyte remained in the oil layer. Nonetheless, efficient energy transfer occurred for analytes 1, 2, 3, and 5 to fluorophore 6, resulting in a strong fluorescent signal at $522 \mathrm{~nm}$. Moreover, the fluorescence emission maxima of analytes 1-5 occur in a spectral region that is likely to have significant 
interference from other analytes. Effectively shifting the fluorescence emission signal to $522 \mathrm{~nm}$ provides a facile way to eliminate undesired spectral interference.

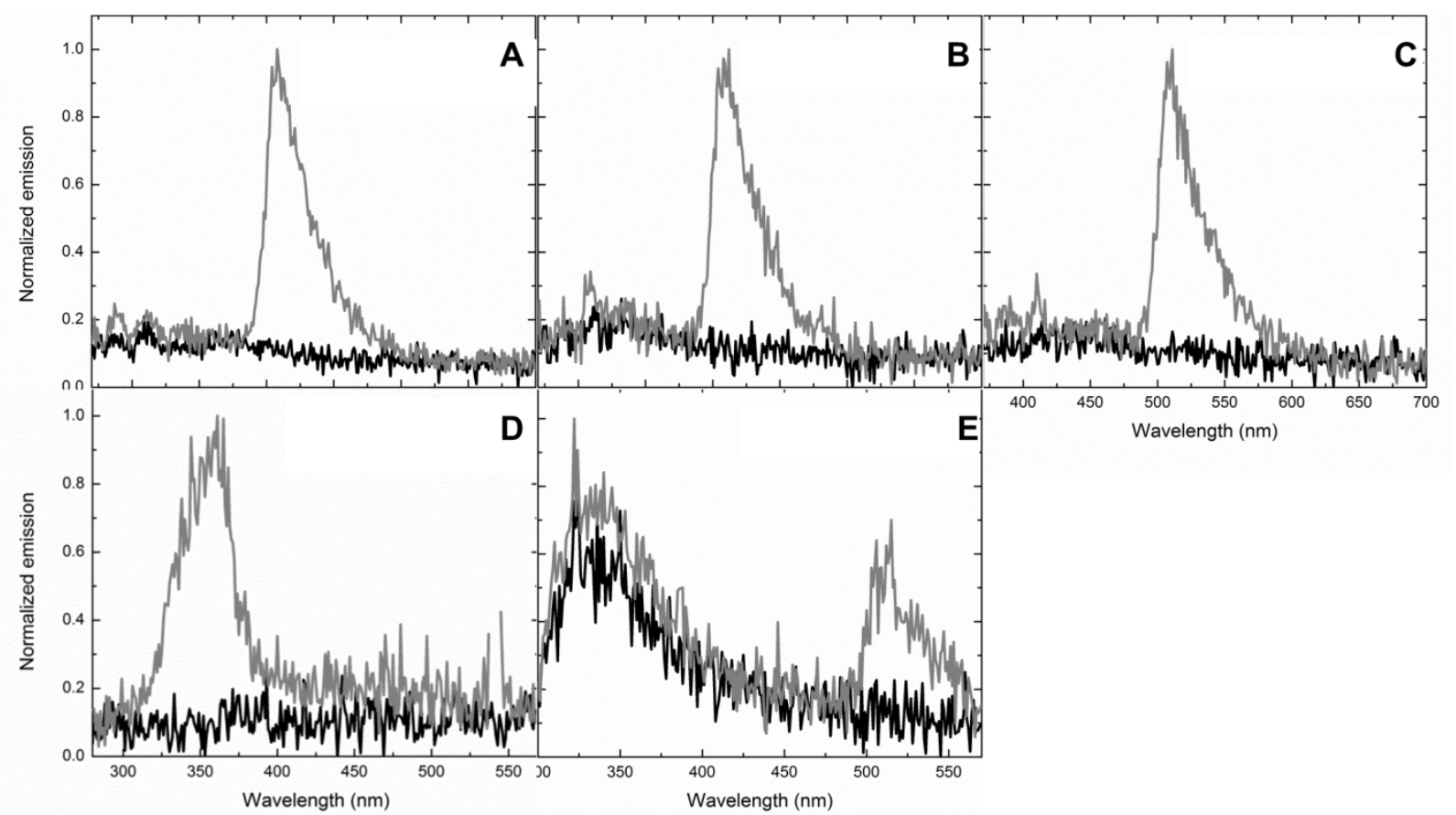

Figure 4. Comparison of the fluorescence emission spectra of analytes in $10 \mathrm{mM} \gamma$-cyclodextrin that was extracted from motor oil in the presence and absence of fluorophore 6. (A) Compound 1; (B) compound 2; (C) compound 3; (D) compound 4; and (E) compound 5. The black line shows the emission spectra in the absence of the fluorophore and the grey line shows the emission spectra in the presence of the fluorophore.[Note that the emission spectrum of Figure 4D has been digitally altered to remove the double harmonic peak at twice the excitation wavelength; a copy of the unaltered spectrum is shown in the ESI].

2c. Innate energy transfer from the oils. In addition to measuring energy transfer efficiencies with analyte-doped samples, the direct energy transfer of the undoped oils to fluorophore $\mathbf{6}$ was measured. These experiments were conducted by adding the fluorophore to the oil-water mixture (in the absence of the analyte), followed by separating the layers. Energy transfer efficiencies 
were measured in the oil layers by exciting the oil at both the analyte excitation wavelength and at the fluorophore excitation wavelength.

The results of these experiments are summarized in Table 4, and indicate some degree of energy transfer for all oils investigated. This energy transfer was most efficient for motor oil, vegetable oil, and pump oil (with $360 \mathrm{~nm}$ excitation), and least efficient for cod liver oil. This data is consistent with literature reports of some degree of PAH contamination in motor oil, vegetable oil, and pump oil, and no PAHs in cod liver oil, ${ }^{29-33}$ and supports the idea that PAHs in the actual oils participate in cyclodextrin-promoted energy transfer.

Table 4. Energy transfer efficiencies from the oil samples directly to fluorophore 6 . $^{a}$

\begin{tabular}{|c|c|c|c|c|c|}
\hline $\begin{array}{c}\text { Excitation } \\
\text { wavelength }\end{array}$ & Motor oil & Vegetable oil & Pump oil & Cod liver oil & $\begin{array}{c}\text { Motor oil- } \\
\text { seawater }\end{array}$ \\
\hline $360 \mathrm{~nm}$ & $20 \pm 3 \%$ & $18 \pm 2 \%$ & $21 \pm 3 \%$ & $7 \pm 1 \%$ & $18 \pm 3 \%$ \\
\hline $270 \mathrm{~nm}$ & $8 \pm 3 \%$ & $b$ & $4 \pm 1 \%$ & $5 \pm 1 \%$ & $8 \pm 2 \%$ \\
\hline $290 \mathrm{~nm}$ & $9 \pm 1 \%$ & $b$ & $5 \pm 1 \%$ & $5 \pm 1 \%$ & $8 \pm 2 \%$ \\
\hline
\end{tabular}

$a$ All values represent an average of at least five trials

$b$ No energy transfer was observed

$2 d$. Control experiments. To ensure that the fluorophore peak defined as energy transfer was a result of actual energy transfer from the analyte to the fluorophore (rather than a result of the fluorophore having a non-zero absorbance at the analyte excitation wavelength), the fluorophore was excited at the excitation wavelength of the analyte $(270 \mathrm{~nm}, 290 \mathrm{~nm}$, and $360 \mathrm{~nm})$ in the presence of the analyte and in the absence of the analyte. The "control ratio" is defined in Equation 3 (above). The results of these experiments are summarized in Table 5.

Table 5. Control ratios for all analytes in the aqueous layer (10 mM $\gamma$-cyclodextrin $)^{\mathrm{a}}$ 


\begin{tabular}{|c|c|c|c|c|c|}
\hline Compound \# & Motor oil & Vegetable oil & Pump oil & Cod liver oil & $\begin{array}{c}\text { Motor oil- } \\
\text { seawater }\end{array}$ \\
\hline $\mathbf{1}$ & $1.14 \pm 0.11$ & $0.95 \pm 0.07$ & $1.07 \pm 0.07$ & $1.03 \pm 0.02$ & $1.06 \pm 0.04$ \\
\hline $\mathbf{2}$ & $1.32 \pm 0.58$ & $1.04 \pm 0.05$ & $1.05 \pm 0.06$ & $1.08 \pm 0.07$ & $1.06 \pm 0.09$ \\
\hline $\mathbf{3}$ & $1.31 \pm 0.58$ & $1.80 \pm 0.47$ & $1.06 \pm 0.03$ & $0.98 \pm 0.12$ & $0.96 \pm 0.01$ \\
\hline $\mathbf{4}$ & $b$ & $b$ & $1.00 \pm 0.41$ & $1.05 \pm 0.02$ & $1.07 \pm 0.02$ \\
\hline $\mathbf{5}$ & $1.17 \pm 0.17$ & $0.99 \pm 0.13$ & $1.02 \pm 0.02$ & $1.05 \pm 0.04$ & $1.02 \pm 0.07$ \\
\hline
\end{tabular}

a All ratios represent an average of at least five trials

$b$ No energy transfer peak was observed

These ratios can be divided into three distinct categories: (1) Ratios between 0.95 and 1.05 indicate that the fluorophore emission from indirect excitation is fundamentally unchanged in the presence or absence of analyte, which indicates that no real energy transfer is occurring; (2) ratios greater than 1.05 indicate that legitimate energy transfer is occurring, because the fluorophore integration is markedly increased in the presence of the analyte; and (c) ratios less than 0.95 indicate that the addition of the analyte leads to fluorescence quenching.

Most of the aqueous extracts demonstrated legitimate energy transfer, especially for highly fluorescent (and toxic) analytes $\mathbf{2}$ and $\mathbf{3}$. Analytes $\mathbf{4}$ and $\mathbf{5}$ demonstrated less interaction with the fluorophore (as indicated by more control ratios between 0.95 and 1.05). This limited interaction is likely a result of the blue-shifted analytes (4 and $\mathbf{5}$ ) having less spectral overlap with fluorophore $\mathbf{6}$ and therefore reduced energy transfer efficiencies. Some degree of spectral overlap is generally understood to be a prerequisite for efficient donor-acceptor interactions and successful energy transfer. ${ }^{47}$ 
2e. Extension to other fluorophores. Another key advantage to non-covalent, proximity-induced energy transfer is its modular nature, which allows for the facile tuning of the fluorescence emission signal through judicious choice of fluorophore. Preliminary investigations towards that end focused on the use of commercially available Rhodamine 6G (compound 7, Chart 1). Three examples are shown in Figure 5, where energy transfer occurred from analytes $\mathbf{1}, \mathbf{2}$, and $\mathbf{3}$ to fluorophore 7 in $12 \%$ efficiency for each case.

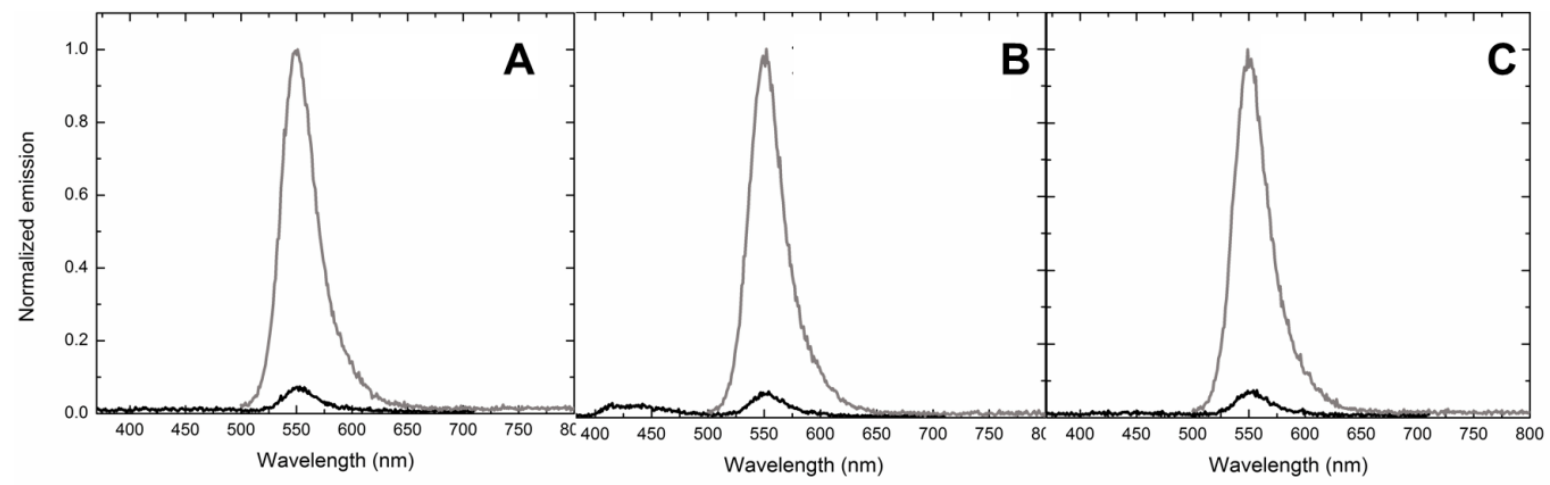

Figure 5. Energy transfer from analytes to fluorophore 7 after extraction from vegetable oil. (A) Compound 1; (B) compound 2; and (C) compound 3. The black line represents analyte excitation and the grey line represents direct fluorophore excitation.

The ability to use multiple fluorophores as energy acceptors allows for the possibility of arraybased detection based on such energy transfer. In such a system, the pattern of interactions of each analyte with an array of fluorophores in cyclodextrin will provide a unique identifier for each analyte. Exposure of the array to an unknown analyte, followed by statistical analysis and pattern matching, will lead to the accurate identification of the unknown. Analogous array-based detection systems have been used for a number of key applications. ${ }^{48,49}$ 
Summary and conclusions. In summary, these experiments report the use of $\gamma$-cyclodextrin for two sequential functions: extraction of carcinogenic analytes from a variety of commercially available oils to an aqueous solution, followed by energy transfer from the analytes to a high quantum yield BODIPY fluorophore. The extraction of analytes into the aqueous layer proceeded with moderate efficiencies, depending on the particular analyte and oil investigated. Even in cases where the extraction efficiency was only modest, good to excellent energy transfer was observed from the newly extracted analyte to fluorophore $\mathbf{6}$. This multi-step system of extraction followed by efficient energy transfer can have significant applications in the development of turn-on detection systems for oil-spill related carcinogens. Efforts towards this goal are in progress, and results will be reported in due course.

\section{ASSOCIATED CONTENT}

Supporting Information. Synthesis of compound 6, details of extraction and energy transfer experiments; summary tables and summary figures for all extraction, energy transfer, and control experiments. This material is available free of charge via the Internet at http://pubs.acs.org.

\section{AUTHOR INFORMATION}

\section{Corresponding Author}

*Department of Chemistry, University of Rhode Island, 51 Lower College Road, Kingston, RI 02881; mlevine@chm.uri.edu; 401-874-4243.

\section{Funding Sources}

This research was funded by a grant from the Gulf of Mexico Research Initiative (GOMRI) and by a Proposal Development Grant from the URI Council for Research. 


\section{REFERENCES}

${ }^{1}$ Akinyokun, O. C.; Inyang, U. G. J. Emerg. Trends Eng. Appl. Sci. 2013, 4, 173.

${ }^{2}$ Pino, V.; Lopez-Darias, J.; German-Hernandez, M.; Afonso, A. M. Adv. Environ. Res. 2011, 9, 181.

${ }^{3}$ Gohlke, J. M.; Doke, D.; Tipre, M.; Leader, M.; Fitzgerald, T. Environ. Health Perspect. 2011, 119, 1062.

${ }^{4}$ Mearns, A. J.; Reish, D. J.; Oshida, P. S.; Ginn, T.; Rempel-Hester, M. A. Water Environ. Res. 2011, 83, 1789.

${ }^{5}$ Barron, M. G. Toxicol. Pathol. 2012, 40, 315.

${ }^{6}$ McNutt, M. K.; Chu, S.; Lubchenco, J.; Hunter, T.; Dreyfus, G.; Murawski, S. A.; Kennedy, D. M. Proc. Natl. Acad. Sci. U.S.A. 2012, 109, 20222.

${ }^{7}$ Radovic, J. R.; Rial, D.; Lyons, B. P.; Harman, C.; Vinas, L.; Beiras, R.; Readman, J. W.; Thomas, K. V.; Bayona, J. M. J. Environ. Manag. 2012, 109, 136.

${ }^{8}$ Chapot, B.; Secretan, B.; Robert, A.; Hainaut, P. Ann. Occup. Hyg. 2009, 53, 485.

${ }^{9}$ Cogliano, V. J.; Baan, R. A.; Straif, K.; Grosse, Y.; Secretan, B.; El Ghissassi, F. Environ. Mol. Mutagen. 2008, 49, 100.

${ }^{10}$ Ylitalo, G. M.; Krahn, M. M.; Dickhoff, W. W.; Stein, J. E.; Walker, C. C.; Lassitter, C. L.; Garrett, E. S.; Desfosse, L. L.; Mitchell, K. M.; Noble, B. T.; Wilson, S.; Beck, N. B.; Benner, R. A.; Koufopoulos, P. N.; Dickey, R. W. Proc. Natl. Acad. Sci. U.S.A. 2012, 109, 20274. 
${ }^{11}$ Perez, C.; Velando, A.; Munilla, I.; Lopez-Alonso, M.; Oro, D. Environ. Sci. Tech. 2008, 42, 707.

${ }^{12}$ Danion, M.; Le Floch, S.; Lamour, F.; Guyomarch, J.; Quentel, C. Ecotoxicol. Environ. Saf. 2011, 74, 2167.

${ }^{13}$ Alonso-Alvarez, C.; Perez, C.; Velando, A. Aquat. Toxicol. 2007, 84, 103.

${ }^{14}$ Allieri, M. A. A. J. Life Sci. 2012, 6, 443.

${ }^{15}$ Hussein, T. A.; Ismail, Z. Z. Environ. Technol. 2013, 34, 351.

${ }^{16}$ Ravelet, C.; Ravel, A.; Grosset, C.; Villet, A.; Geze, A.; Wouessidjewe, D.; Peyrin, E. J. Liq. Chromatogr. Relat. Technol. 2002, 25, 421.

17 Petitgirard, A.; Djehiche, M.; Persello, J.; Fievet, P.; Fatin-Rouge, N. Chemosphere 2009, 75, 714 .

${ }^{18}$ Gruiz, K.; Fenyvesi, E.; Kriston, E.; Molnar, M.; Horvath, B. J. Inclusion Phenom. Mol. Recognit. Chem. 1996, 25, 233.

${ }^{19}$ Lieberzeit, P. A.; Dickert, F. L. Anal. Bioanal. Chem. 2007, 387, 237.

${ }^{20}$ Stanley, S.; Percival, C. J.; Auer, M.; Braithwaite, A.; Newton, M. I.; McHale, G.; Hayes, W. Anal. Chem. 2003, 75, 1573.

${ }^{21}$ Poster, D. L.; Schantz, M. M.; Sander, L. C.; Wise, S. A. Anal. Bioanal. Chem. 2006, 386, 859.

${ }^{22}$ Frysinger, G. S.; Gaines, R. B.; Xu, L.; Reddy, C. M. Environ. Sci. Tech. 2003, 37, 1653. 
${ }^{23}$ Wang, H. M.; Wenz, G. Chem. Asian J. 2011, 6, 2390.

${ }^{24}$ Serio, N.; Miller, K.; Levine, M. Chem. Commun. 2013, 49, 4821.

${ }^{25}$ Mako, T.; Marks, P.; Cook, N.; Levine, M. Supramol. Chem. 2012, 24, 743.

${ }^{26}$ Serio, N.; Chanthalyma, C.; Prignano, L.; Levine, M. Supramol. Chem. 2013, accepted.

${ }^{27}$ Scholes, G. D.; Harcourt, R. D.; Ghiggino, K. P. J. Chem. Phys. 1995, 102, 9574.

${ }^{28}$ Rose, A.; Tovar, J. D.; Yamaguchi, S.; Nesterov, E. E.; Zhu, Z.; Swager, T. M. Phil. Trans. Math. Phys. Eng. Sci. 2007, 365, 1589.

29 Poster, D. L.; Kucklick, J. R.; Schantz, M. M.; Porter, B. J.; Leigh, S. D.; Wise, S. A. Anal. Bioanal. Chem. 2003, 375, 223.

30 Jaouen-Madoulet, A.; Abarnou, A.; Le Guellec, A.-M.; Loizeau, V.; Leboulenger, F. J. Chromatogr. A 2000, 886, 153.

31 Dost, K.; Ideli, C. Food Chem. 2012, 133, 193.

32 Zhao, Q.; Wei, F.; Luo, Y.-B.; Ding, J.; Xiao, N.; Feng, Y.-Q. J. Agr. Food Chem. 2011, 59, 12794.

33 Peacock, E. E.; Arey, J. S.; De Mello, J. A.; McNichol, A. P.; Nelson, R. K.; Reddy, C. M. Energy Fuels 2010, 24, 1037.

${ }^{34}$ Diehl, K. L.; Anslyn, E. V. Chem. Soc. Rev. 2013, 42, 8596.

${ }^{35}$ Bunz, U. H. F.; Rotello, V. M. Angew. Chem. Int. Ed. 2010, 49, 3268. 
${ }^{36}$ Shepherd, J. L.; Kell, A.; Chung, E.; Sinclar, C. W.; Workentin, M. S.; Bizzotto, D. J. Am. Chem. Soc. 2004, 126, 8329.

${ }^{37}$ Fluorophore $\mathbf{6}$ was synthesized in the laboratory for a project on fluorescently-tagged polyamines; results with this fluorophore have been shown to be indistinguishable from an unfunctionalized BODIPY; see reference 24.

${ }^{38}$ Gao, H.; Miles, M. S.; Meyer, B. M.; Wong, R. L.; Overton, E. B. J. Environ. Monit. 2012, $14,2164$.

${ }^{39}$ Olkowska, E.; Polkowska, Z.; Namiesnik, J. Chem. Rev. 2011, 111, 5667.

${ }^{40}$ Asadov, Z. H.; Tantawy, A. H.; Zarbaliyeva, I. A.; Rahimov, R. A.; Ahmadova, G. A. Chem. J. 2012, 2, 136.

${ }^{41}$ Ryzhenko, B. N.; Cherkasova, E. V. Geochem. Int. 2012, 50, 1101.

42 Breslow, R.; Rizzo, C. J. J. Am. Chem. Soc. 1991, 113, 4340.

${ }^{43}$ Gibb, C. L. D.; Gibb, B. C. J. Am. Chem. Soc. 2011, 133, 7344.

${ }^{44}$ Ma, Y.-G.; Lei, Y.-D.; Xiao, H.; Wania, F.; Wang, W.-H. J. Chem. Eng. Data 2010, 55, 819.

${ }^{45}$ Delistraty, D. Toxicol. Environ. Chem. 1997, 64, 81.

${ }^{46}$ Sadikovic, B.; Rodenhiser, D. I. Toxicol. Epigenetics 2012, 111.

${ }^{47}$ Andrew, T. L.; Swager, T. M. J. Polym. Sci. B Polym. Phys. 2011, 49, 476.

${ }^{48}$ Bunz, U. H. F.; Rotello, V. M. Angew. Chem. Int. Ed. 2010, 49, 3268. 
${ }^{49}$ Ivy, M. A.; Gallagher, L. T.; Ellington, A. D.; Anslyn, E. V. Chem. Sci. 2012, 3, 1773. 
TABLE OF CONTENTS GRAPHIC:

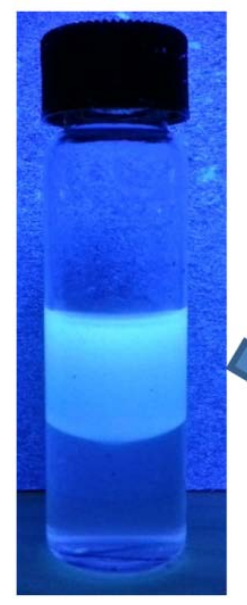

extraction

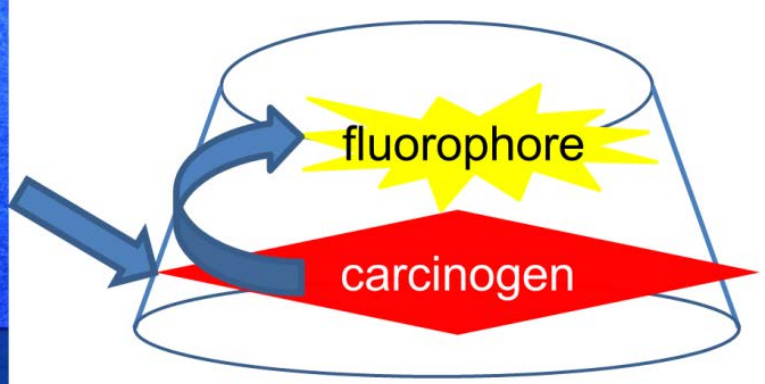

energy transfer 